\title{
Jehovah's Witness survives severe favism complications: Advance provisions of treatment and new challenges for the physicians
}

\author{
Massimo Salvetti, ${ }^{1}$ Sara Capellini, ${ }^{1}$ Paola Delbon, ${ }^{2}$ Francesca Maghin, ${ }^{3}$ \\ Maria Lorenza Muiesan, ${ }^{1}$ Adelaide Conti ${ }^{2,3}$ \\ ${ }^{1}$ Internal Medicine, Department of Clinical and Experimental Sciences, University of Brescia and ASST \\ Spedali Civili of Brescia; ${ }^{2}$ Centre of Bioethics Research, Department of Medical and Surgical Specialties, \\ Radiological Sciences and Public Health, University of Brescia; ${ }^{3}$ Forensic Medicine Unit, Department of \\ Medical and Surgical Specialties, Radiological Sciences and Public Health, University of Brescia and ASST \\ Spedali Civili of Brescia, Brescia, Italy
}

\begin{abstract}
The management of an acute hemolytic event in a patient suffering from favism is based on transfusion support to ensure adequate tissue oxygenation. If this measure could not be pursued, in case of severe anemia the risk of death from multiorgan failure would be relevant. Most of Jehovah's Witness decline transfusion of whole blood and its main components, even in life-threatening situations. In this context, the treatment of severe anemia in these patients still represents a challenge from both medical and legal
\end{abstract}

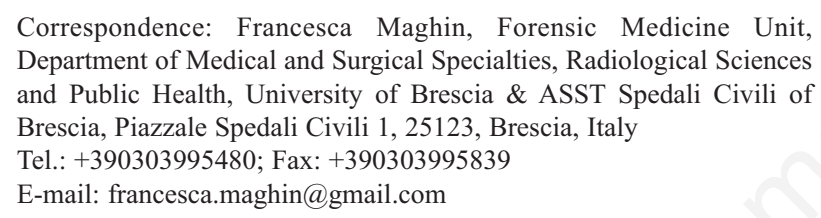

Contributions: All authors listed on the title page contributed to the writing of the manuscript, attest to the validity and legitimacy of the data and its interpretation. No persons other than the authors listed have contributed significantly to the preparation of the manuscript.

Conflicts of interest: None. This work was not supported by any grant. Availability of data and materials: All data generated or analyzed during this study are included in this published article.

Ethics approval and consent to participate: Not applicable. This article does not contain any studies with human participants performed by any of the authors.

Consent for publication: Not applicable.

Received for publication: 9 March 2021.

Revision received: 7 April 2021.

Accepted for publication: 7 April 2021.

This work is licensed under a Creative Commons Attribution 4.0 License (by-nc 4.0).

CCopyright: the Author(s), 2021

Licensee PAGEPress, Italy

Emergency Care Journal 2021; 17:9738

doi:10.4081/ecj.2021.9738 stand points. Authors report a case of a Jehovah's Witness suffering from favism who refused blood transfusion, surviving a severe event of critical anemia associated with acute renal failure, thanks to the application of alternative therapies. It is essential that clinicians know the medico-legal aspects in such situations and are able to act promptly to support the patient's vital functions, by complying with his/her wishes.

\section{Introduction}

Glucose-6-Phosphate-Deydrogenase (G6PD) deficiency is the most common enzymatic hereditary disorder of red blood cells (RBCs). It is an X-linked recessive inherited genetic disorder in which a mutation of the G6PD gene results in an inefficient or absent expression and corresponding enzyme deficiency. More than 140 mutations have been identified.

The National Organization for Rare Disorders estimates that 400 million people worldwide are affected. G6PD deficiency is global in its distribution, with the highest prevalence reported in Africa, southern Europe, the Middle East, southeast Asia, and the central and southern Pacific islands. However, because of fairly recent migration, deficient alleles are nowadays quite prevalent in North and South America and in northern Europe. This geographic distribution is highly correlated with regions in which malaria was once endemic, leading to the hypothesis that G6PD deficiency may have conferred a selective advantage against the infection by Plasmodium falciparum, similar to observations made with other RBC abnormalities. ${ }^{1-3}$ G6PD deficiency makes red cells highly vulnerable to oxidative damage, and therefore susceptible to hemolysis. The most frequent clinical manifestations of G6PD deficiency are neonatal jaundice, and acute hemolytic anemia, which is usually triggered by an exogenous agent (such as ingestion of fava beans, drug treatment with primaquine, cloroquine or rasburicase, or more rarely infections). Some G6PD variants cause chronic hemolysis, leading to congenital non-spherocytic hemolytic anemia.

The management of an acute hemolytic event in a patient suffering from favism, once the trigger has been identified and the cause of the event has been eliminated, is based exclusively on transfusion support to ensure adequate tissue oxygenation. If this measure could not be pursued, in case of severe anemia the risk of death from multiorgan failure would be relevant.

We report a case of a Jehovah's Witness suffering from favism, surviving a severe event of critical anemia associated with acute renal failure, who refused blood transfusion. 
Table 1. Laboratory findings at admission (Emergency Room - ER) and during hospital stay.

\begin{tabular}{|c|c|c|c|c|c|c|c|c|c|c|}
\hline & $\begin{array}{l}2 / 05 \\
\text { ER }\end{array}$ & $3 / 05$ & $4 / 05$ & $6 / 05$ & $8 / 05$ & $13 / 05$ & 22/05 & $27 / 05$ & $13 / 06$ & $\begin{array}{c}1 / 07 \\
\text { Discharge }\end{array}$ \\
\hline $\mathrm{Hb}(\mathrm{g} / \mathrm{dL})(14-18 \mathrm{~g} / \mathrm{dL})$ & 9.7 & 5.9 & 3.8 & 3.1 & 4.2 & 6 & 7.4 & 8.2 & 9.3 & 11.4 \\
\hline Reticolocytes (\%) (0.7-2\%) & & 8.73 & & 24 & 28 & 26.73 & 2.68 & 1.42 & & \\
\hline Reticolocytes (n/uL) (38000-109000/uL) & & 139000 & & 187000 & 286000 & 404000 & 53000 & 35000 & & \\
\hline WBC (n/uL) (4000-10600/uL) & 25960 & 30520 & 41820 & 34260 & 29900 & 10870 & 8220 & 4930 & 6500 & 8780 \\
\hline CRP (mg/L) vn $<5$ mg/L & 124 & 132 & 174 & & 39.5 & 14.7 & 12.5 & 11.3 & 2.1 & \\
\hline Total Bilirubin (mg/dL) $(<1.2 \mathrm{mg} / \mathrm{dL})$ & 3.21 & 2.88 & 2.94 & 0.92 & 0.61 & 0.36 & - & 0.26 & & \\
\hline Indirect Bilirubin (mg/dL) (0.2-0.9 mg/dL) & 2.79 & 2.48 & 2.45 & - & - & - & - & - & & \\
\hline LDH (U/L) (135-225 U/L) & HEMOLYSIS & HEMOLYSIS & HEMOLYSIS & 2947 & - & 1058 & 379 & 283 & & \\
\hline Creatinine (mg/dL) (0.7-1.2 mg/dL) & 1.56 & 3.35 & 5.3 & 6.49 & 6.6 & 6.58 & 5.72 & 4.95 & 2.88 & 1.66 \\
\hline PCT $(\mathrm{ng} / \mathrm{mL})(<0.5 \mathrm{ng} / \mathrm{mL})$ & & 3.61 & & & & & 0.28 & & & \\
\hline
\end{tabular}

\section{Case Report}

Here we present the case of a 49 -years-old male patient of Sardinian origin, with a positive family history of favism (mother, father and brother). The patient was affected by type 2 diabetes mellitus and dyslipidemia, respectively treated with metformin and fenofibrate. He accessed the emergency department for pain in the lumbar region bilaterally irradiated to the lower limbs, hyperpyrexia $\left(38^{\circ} \mathrm{C}\right)$ and hyperchromic urine. Blood chemistry tests showed leukocytosis (WBC 25960/uL), moderate macrocytic anemia (Hb $9.7 \mathrm{~g} / \mathrm{dL}, \mathrm{MCV} 105 \mathrm{f} / \mathrm{L})$, indirect hyperbilirubinemia $(2.79 \mathrm{mg} / \mathrm{dL})$ and increased CRP (124 mg/L) (Table 1). Urine and hemocultures were collected and resulted all negative. Chest X-ray and abdominal ultrasound were also normal.

Upon the finding of severe desaturation at peripheral oximetry $\left(\mathrm{SpO}_{2} 70 \%\right)$, arterial blood gas analysis was undertaken, reporting $\mathrm{pO}_{2}$ values at the lower normal limits and methemoglobinemia, which justified the low peripheral oxygen saturation (Table 2). In the ER the patient was treated with high flow oxygen by a reservoir mask; intravenous paracetamol was given to control lumbar pain.

The patient was therefore admitted to the Internal Medicine Ward (semi-intensive unit) with the diagnosis of acute hemolysis. At physical examination, the presence of scleral jaundice was the only pathological finding. Further blood tests confirmed a rapidly progressive hemolytic anemia: decreasing hemoglobin values, reticulocytosis, indirect hyperbilirubinemia, increased lactate dehydrogenase and reduced haptoglobin were the major findings. Among the causes of hemolysis both the intake of drugs other than those chronically taken and, through laboratory and instrumental investigations, an underlying infectious trigger were excluded. Direct and indirect Coombs test, ANA, ENA, ANCA, blood smear, folate levels, B12 vitamin levels, iron levels, typing for paroxysmal nocturnal hemoglobinuria, lymphocyte typing were performed to exclude other causes of anemia, including autoimmune hemolytic anemia and were all negative. No abnormalities in hepatic function were detected.

The patient, on the other hand, reported the intake of fresh broad beans two days earlier, reiterating that it was not the first time in his life. The progressive decrease in hemoglobin values led to the indication for a red blood cell transfusion, a procedure that, however, was sharply declined by the patient the first day and by his wife thereafter because his religious beliefs (he reported to be a Jehovah's Witness - JW) forbid the administration of any blood derivative. To this regard the wife presented an official document reporting his anticipated health treatment provisions (Italian
Table 2. Arterial blood gas analysis performed at admission (Emergency Room - ER).

\section{Arterial blood gas analysis (ER) \\ (without oxygen support, $\mathrm{FiO}_{2} 21 \%$ )}

$\mathrm{pH}$

7.5

$\mathrm{pO}_{2}$ $53 \mathrm{mmHg}$

$\mathrm{pCO}_{2}$ $35 \mathrm{mmHg}$

$\mathrm{HCO}^{3-}$ $27.7 \mathrm{mmol} / \mathrm{L}$

$\mathrm{SO}_{2}$ $94.3 \%$

$\mathrm{Hb}$ $7.7 \mathrm{~g} / \mathrm{dL}$

$\mathrm{O}_{2} \mathrm{Hb}$

$79.7 \%$

$\mathrm{COHb}$

MetHb (1.5-2\%)

$3.8 \%$

Lactate $(0.6-1.8 \mathrm{mmol} / \mathrm{L})$

$11.7 \%$

$1.9 \mathrm{mmol} / \mathrm{L}$

Disposizioni Anticipate di Trattatmento, DAT), thus preventing health providers from transfusion support even in a "state of need" (patient unable to express his wishes). The patient's DAT reported his unwillingness for invasive treatments in case of life-threatening conditions for which an unfavourable evolution could have been predicted.

He therefore underwent supportive therapy with saline (2000 $\mathrm{mL} / 24$ hours), glucose solution $5 \%$ (1000 mL/24 hours), albumin (4 $\mathrm{g}$ in $100 \mathrm{~mL} / 24$ hours), bicarbonate solution and high-flow oxygen therapy (reservoir mask $15 \mathrm{~L} / \mathrm{min}$ ). In addition intravenous folate $(25 \mathrm{mg}$ od), intramuscular B12 vitamin (1000 mg od), intravenous ferric carboxymaltose (1500 mg od), intramuscular erythropoietin (10000 U once week), intravenous furosemide, and empiric antibiotic therapy (piperacillin/ tazobactam and vancomycin according to renal function).

At first these measures did not prevent the patient from developing coma, in the presence of critical anemia (minimum hemoglobin value $3.1 \mathrm{~g} / \mathrm{dL}$ ) associated with acute renal failure (maximum creatinine $6.6 \mathrm{mg} / \mathrm{dL}$ ) which reached the most critical point in the seventh day from the intake of the beans. The patient developed an acute renal failure (maximum creatinine $6.6 \mathrm{mg} / \mathrm{dL}$ ) but he didn't need dialytic treatment. We discussed the case and planned the management together with nephrologists, haematologists and intensivists. However, neither intensive care nor hemodialytic support were deemed necessary at any moment. 
The treatment with saline, glucose solution, bicarbonate solution, ev albumin and furosemide, empiric antibiotic therapy (piperacillin/tazobactam and vancomycin with dose adjustment for renal function) was maintained for several days until a slow but progressive improvement of the parameters was observed. B12 vitamin (im $1000 \mathrm{mg}$ od), folate (ev $25 \mathrm{mg}$ od), im epoietin (10000 $\mathrm{U} /$ week) and high-flow oxygen therapy were also maintained; treatment with ferric carboxymaltose $(1500 \mathrm{mg}$ od) was followed by oral ferrous sulfate (105 $\mathrm{mg}$ od).

The patient was discharged home with restoration of adequate hemoglobin $(\mathrm{Hb} 11.7 \mathrm{~g} / \mathrm{dL})$ and creatinine $(1.66 \mathrm{mg} / \mathrm{dL})$ values after 60 days of hospitalization. Before being discharged, the G6PD activity was determined and confirmed the diagnosis of favism (G6PD activity $0.66 \mathrm{U} / \mathrm{g} \mathrm{Hb}$, normal values 10.10-14.19).

\section{Discussion}

There are over 8.5 million practicing JW worldwide, most will decline transfusion of whole blood and its main components - red blood cells, plasma, platelets, and white blood cells, even in lifethreatening situations. This decision is based on the interpretation of several Bible passages whence transfusions are considered a disassociating offense by the majority of JW followers. ${ }^{4}$

A multifaceted approach to the treatment of life-threatening anemia in JW patients was proposed by Posluszny and Napolitano. ${ }^{5}$ Briefly, the Authors recommend intravenous or subcutaneous epoetin alfa at a dose of 40,000 units daily until hemoglobin recovers to greater than $7 \mathrm{~g} / \mathrm{dL}$ to promote erythropoiesis. By contrast, treatment with low-dose epoetin beta $(<600$ $\mathrm{IU} / \mathrm{kg} /$ week) was not effective in reducing duration of anemia or mortality in JW. ${ }^{6}$ Other supportive therapies should include iron (100 mg intravenous iron sucrose formulation od), vitamin C (500 $\mathrm{mg}$ orally three times a day), folate (1 mg orally or intravenously od), and vitamin B12 (1 mg orally od) supplements. ${ }^{5}$ For patients "critically ill" (with increase in lactate and base deficit, hemodynamic instability, hypoperfusion or shock) experimental hemoglobin-based oxygen carrier (HBOC) therapy and subsequent monitoring for adverse effects can also be considered. ${ }^{5}$ Finally, attempts must be made to reduce the risk of iatrogenic anemia, limiting laboratory testing as much as possible. ${ }^{6}$

In case of emergency the initiation of life-saving blood transfusion to JW patient who cannot express his or her wishes (e.g., unconscious, dementia or ongoing psychiatric condition) depends on an advance directive.

According to the Italian Law, every person of age and capable of understanding and willing, in anticipation of a possible future inability to self-determine and after having acquired adequate medical information on the consequences of his/her choices, can express his/her wishes on the matter of health treatments, as well as the consent or refusal with respect to diagnostic tests or therapeutic choices and to individual health treatments through the advance treatment provisions (DAT). ${ }^{7}$ Law 219 also provides for the possibility of indicating in the DAT a trustee - whose choice is completely left to the will of the settlor - who is called upon to represent the interested party in relation with doctors and health facilities. The doctor is required to comply with the DAT, which can be disregarded, in whole or in part, by the doctor himself, in agreement with the trustee if they appear clearly incongruous or do not correspond to the current clinical condition of the patient or if there are unpredictable therapies upon subscription, capable of offering concrete possibilities for improving living conditions. In the event of a conflict between the trustee and the doctor, the decision is left to the tutelary judge. ${ }^{7}$

In the case we described above supportive treatments were effective to timely restore adequate hemoglobin levels thus preventing the occurrence of multiorgan failure. However, even though the patient remained conscious and did not encounter a real "state of need" throughout his hospitalization, his/her written provisions together with the continuative presence of a trustee would have prevented us from practicing transfusion support.

In a recent ruling, relating to a fact prior to Law no. 219/2017, the Supreme Court (Cass. Civ., Section III, 23 December 2020, n. 29469) has stated the following principle: the patient has the right to refuse the blood transfusion, asserting the right of self-determination in the matter of health treatments to protect the freedom to profess his/her religious faith. The refusal can also be formulated with a declaration made before the treatment itself, provided that the will to prevent the transfusion emerges unequivocally, even in the hypothesis of life threatening.

Jurisprudence (Cass. Civ., Section III, 15 September 2008, n. 23676) has long recognized the patient's right to refuse medical treatment administered to him/her, even when such refusal may cause his/her death, from the moment in which the patient has been fully informed about the severity of his/her situation and about the risks of refusing treatment. ${ }^{8}$

In conclusion, the treatment of life-threatening anemia in JW patients still represents a challenge from both medical and legal stand points. From a medical point of view, the treatment of a patient without blood transfusion has always been an ethical problem that afflicts the physician, who may feel that complying with the patient's wishes will force them to provide suboptimal care. ${ }^{9,10}$ On the other hand, clinicians can create opportunities to provide quality care for all patients, if they accept the challenges of learning how to treat patients safely and successfully without the traditional treatment of blood transfusion. ${ }^{11-12}$ From a legal point of view, the value given to anticipated medical provisions in many Countries represents a fundamental milestone and a defense for healthcare providers who, by complying with the patients' wishes, are no longer liable for failure to render assistance.

\section{References}

1. Luzzatto L, Ally M, Notaro R. Glucose-6-phosphate dehydrogenase deficiency. Blood 2020;136:1225-40.

2. Luzzatto L, Arese P. Favism and Glucose-6-Phosphate Dehydrogenase Deficiency. N Engl J Med 2018;378:60-71.

3. Cappellini MD, Fiorelli G. glucose-6-phosphate dehydrogenase deficiency. Lancet 2008; 371:364.

4. Crowe EP, DeSimone RA. Transfusion support and alternatives for Jehovah's Witness patients. Curr Opin Hematol 2019; 26:473-9.

5. Posluszny JA Jr, Napolitano LM. How do we treat life-threatening anemia in a Jehovah's Witness patient? Transfusion 2014; 54:3026-34.

6. Beliaev AM, Allen SJ, Milsom P, et al. Low-dose erythropoietin treatment is not associated with clinical benefits in severely anaemic Jehovah's Witnesses: a plea for a change. Blood transfusion 2018;16:53-62.

7. Law no. 219 of December 22nd 2017, "Norme in materia di consenso informato e di disposizioni anticipate di trattamento", Article 4. (GU Serie Generale n.12 del 16-01-2018). Permalink: https://www.gazzettaufficiale.it/eli/id/2018/1/16/ 


\section{$18 \mathrm{G} 00006 / \mathrm{sg}$}

8. Delbon P, Salvetti M, Paini A, et al. Refusal of blood transfusion by Jehovah's Witnesses in Italy: legal and ethical issues. Minerva Medicolegale 2017;137:37-42.

9. Johnson-Arbor K, Verstraete R. No bad blood - surviving severe anemia without transfusion. JAMA Internal Medicine 2021;181:7-8.

10. Schechter DC. Problems relevant to major surgical operations in Jehovah's Witnesses. Am J Surg 1968;116:73-80.

11. De Michelis C. Transfusion refusal and the shifting limits of multicultural accommodation. Qual Health Res 2017;27:215061.

12. Crowe EP, DeSimone RA. Transfusion support and alternatives for Jehovah's Witness patients. Curr Opin Hematol 2019;26:473-9. 